\title{
TÁTICAS REPRODUTIVAS DE Mimagoniates microlepis (STEINDACHNER, 1876) (CHARACIDAE, GLANDULOCAUDINAE) NO RIO COLÔNIA PEREIRA, PARANAGUÁ, PARANÁ
}

\author{
Reproductive tactics of Mimagoniates microlepis (Steindachner, 1876) \\ (CHARACIDAE, GLANDULOCAUDINAE) at Colônia Pereira \\ River, Paranaguá, Paraná
}

\author{
Marcelo Rennó Braga ${ }^{1}$ \\ MárciaSantos deMenezes ${ }^{2}$ \\ JoséMarceloRochaAranha
}

\section{Resumo}

O estudo foi realizado no rio Colônia Pereira, pertencente à região hidrográfica Atlântico Sul. Foram feitas 13 coletas mensais entre março de 1995 e março de 1996, utilizando-se pesca elétrica. Foi determinada a variação da proporção sexual mensalmente e por classes de tamanho. Foi estimado o comprimento médio da primeira maturação $\left(\mathrm{L}^{50}\right)$ e o comprimento médio em que $100 \%$ dos indivíduos são adultos $\left(\mathrm{L}^{100}\right)$. A época reprodutiva foi determinada baseada na freqüência de indivíduos em reprodução e pela variação temporal da relação gonadossomática (RGS) para machos e fêmeas. Foi capturado e dissecado um total de 233 espécimens. A proporção sexual para o período como um todo foi de 1:1 e mensalmente houve predomínio de fêmeas no mês de junho e de machos nos meses de setembro e outubro. Houve predomínio significativo de fêmeas nas classes de menor comprimento e de machos nas classes de maior comprimento. $\mathrm{OL}_{50}$ de machos e fêmeas foi estimado dentro da classe de comprimento $3(\vdash 3,5 \mathrm{~cm}) \mathrm{e}$ o $\mathrm{L}_{100}$ de machos e fêmeas foi estabelecido dentro da classe de comprimento $6(4,5 \mathrm{H} 5 \mathrm{~cm})$. O período reprodutivo de Mimagoniates microlepis ocorreu durante a primavera e verão e é sincronizado com o regime das chuvas.

Palavras-chave: Reprodução; Piaba-azul; Floresta Atlântica; Rios costeiros; Peixe.

\footnotetext{
Mestre em Zoologia pela Universidade Federal do Paraná. e-mail: marcelobraga@onda.com.br

Doutora em Ecologia e Recursos Naturais pela Universidade Federal de São Carlos. e-mail: marciamenezes@unicenp.edu.br

Doutor em Ecologia e Recursos Naturais pela Universidade Federal de São Carlos, Laboratório de Ecologia de Rios, Departamento de Zoologia, UFPR.e-mail:jmaranha@ufpr.br
} 


\section{Abstract}

The study was realized at Colônia Pereira river witch belongs to hydrographic region of South Atlantic. Thirteen samples were conducted monthly from March of 1995 to March of 1996 and electric fishing was the sample technique used. The variation of sexual ratio was determined monthly and between length classes. The average length at the first sexual maturity $\left(\mathrm{L}^{50}\right)$ and the average length when $100 \%$ of individuals are adults $\left(\mathrm{L}^{100}\right)$ were calculated. The reproduction period was determined based on the frequency of individuals sexually active and by the variation of the of the gonosomatic relation (RGS), both for males and females. 233 specimens were captured and dissected. The sexual ratio for the whole study was 1:1 and monthly there was a predominance of females in June and of males in September and October. Females were predominant in smaller length classes and males were predominant in bigger length classes. The $\mathrm{L}_{50}$ for males and females was estimated inside a length class of $3 \vdash 3.5 \mathrm{~cm}$ and the $\mathrm{L}_{100}$ for males and females was inside a length class of $64.5+5 \mathrm{~cm}$. The reproductive period of Mimagoniates microlepis occurred during spring and summer and was synchronized with rain regime.

Keywords: Reproduction; Blue tetra; Atlantic rain forest; Coastal Stream; Fish.

\section{Introdução}

As espécies de peixes apresentam variadas estratégias de vida, as quais permitem a sobrevivência destes organismos em distintos hábitats. Dentre as estratégias de vida está a estratégia reprodutiva, que é o conjunto de características que uma espécie manifesta para ter sucesso na reprodução, mantendo populações viáveis (1). Em geral, essas características estão associadas a condições favoráveis de desenvolvimento de ovos e larvas, como locais e épocas que apresentam maior disponibilidade de alimento e abrigo (2). Existe, então, um conjunto de táticas que define uma determinada estratégia de reprodução e entre tais táticas são abordadas neste estudo: o período reprodutivo, o comprimento médio da primeira maturação, o comprimento médio em que toda população se apresenta madura, a proporção de ambos os sexos ao longo do tempo e em diferentes fases de desenvolvimento.

Os estudos sobre reprodução de peixes são ferramentas importantes para compreensão de mecanismos adaptativos e, portanto, fundamentais para elaboração de ações de conservação e manejo das espécies. Dentro deste contexto, a espécie de peixe Mimagoniates microlepis habita um dos ambientes mais ameaçados do planeta, que é a Floresta Atlântica (3). Sua distribuição geográfica é ampla, ocorrendo em rios costeiros do sul da Bahia até o norte do Rio Grande do Sul, sendo também encontrado em algumas áreas do alto rio Iguaçu (4) e recentemente uma nova ocorrência foi registrada na bacia do rio Tibagi (5). Taxonomicamente, a espécie pertence à ordem Characiformes, família Characidae e subfamília Glandulocaudinae. M. microlepis é uma espécie de pequeno porte, atinge em torno de seis centímetros em ambiente natural e apresenta coloração azulada. Tais características despertam o interesse de aquaristas que conhecem a espécie pelos nomes populares de Piaba-azul e Blue-tetra. Características marcantes da espécie são o dimorfismo sexual, em que machos apresentam tecido glandular e escamas modificadas em suas nadadeiras caudais, e reprodução com inseminação, onde fêmeas inseminadas retêm células espermáticas em seus ovários, não há evidência de fertilização nos ovários e por este motivo evita-se o termo fertilização interna $(6,7)$.

Considerando a importância de se conhecer a biologia de espécies que habitam um bioma que está entre os mais ricos e ameaçados do planeta, é apresentado aqui um conjunto de informações sobre reprodução de $M$. microlepis em um rio litorâneo paranaense.

\section{Material e métodos}

O estudo foi realizado no rio Colônia Pereira, pertencente à região hidrográfica Atlântico Sul, de acordo com a resolução do Conselho Nacional de Recursos Hídricos n. 32, de 15 de outubro de 2003 (8). Este rio nasce na Serra da Prata, no Parque Nacional Saint-Hilaire/Hugo Lange, a uma altitude de $650 \mathrm{~m}$ acima do nível do mar e deságua no rio das Pombas, tributário do rio Guaraguaçu, que deságua na Baía de Paranaguá, no Paraná. Caracteriza-se por fundo predominantemente arenoso, água moderadamente turva de pequena profundidade (até dois metros), vegetação marginal composta de árvores, arbustos e gramíneas parcialmente submersas. O clima na região é tropical, superúmido, sem estação seca e isento de geadas (9). As chuvas são bem distribuídas 
durante o ano todo, sendo que no mês mais seco, julho, há precipitações de até $60 \mathrm{~mm}$ e fevereiro é o mês mais chuvoso. Anualmente, os níveis pluviométricos são superiores a $1000 \mathrm{~mm}$ e a temperatura média anual varia de $17^{\circ} \mathrm{C}$ a $21^{\circ} \mathrm{C}(9)$.

Foram realizadas 13 coletas mensais entre março de 1995 e março de 1996, utilizando-se pesca elétrica em um trecho aproximado de 50 metros do rio. Os peixes foram fixados e analisados em laboratório. Foram obtidos dados de comprimento total (Lt) e peso (Wt) de cada indivíduo capturado, em seguida foram dissecados para identificação do sexo e com o auxílio de microscópio estereoscópico foi feito o reconhecimento macroscópico do estádio de desenvolvimento gonadal segundo escala proposta por Vazzoler (1). As gônadas foram retiradas e pesadas em balança de precisão $0,001 \mathrm{~g}$. Foi determinada a variação da proporção sexual mensalmente. Para analisar a proporção sexual por tamanho e para determinar o comprimento médio da primeira maturação $\left(\mathrm{L}_{50}\right)$ e o comprimento médio em que $100 \%$ dos indivíduos são adultos $\left(\mathrm{L}_{100}\right)$, foram estabelecidas classes de tamanho de acordo com a metodologia proposta por Sturges (10). A época reprodutiva foi determinada baseada na freqüência de indivíduos em reprodução e pela variação temporal da relação gonadossomática (RGS) para machos e fêmeas, sendo que foram considerados reprodutivos os indivíduos em maturação e maduros e não reprodutivos indivíduos imaturos e esvaziados.

\section{Resultados}

Foi capturado e dissecado um total de 233 espécimes. Em dezenove indivíduos, não foi possível identificar precisamente o sexo, portanto estes foram excluídos da maior parte das análises. Foram estabelecidas oito classes de comprimento, cujos intervalos estão representados na Tabela 1 .

A proporção sexual para o período como um todo foi de 1:1 $\left(\mathrm{x}^{2}=3,66, \mathrm{p}<0,05\right)$. Mensalmente, houve predomínio de fêmeas no mês de junho $\left(\mathrm{x}^{2}=7,11\right.$, $\mathrm{p}<0,05)$ e de machos nos meses de setembro $\left(\mathrm{x}^{2}=4,76\right.$,

\section{TABELA 1 - Intervalos de cada classe de comprimento de Mimagoniates microlepis no rio Colônia Pereira}

\begin{tabular}{ll}
\hline 1 & $2,0{ }_{-} 2,5$ \\
2 & $2,5{ }_{-} 3,0$ \\
3 & $3,0{ }_{-} 3,5$ \\
4 & $3,5{ }_{-} 4,0$ \\
5 & $4,0{ }_{-} 4,5$ \\
6 & $4,5{ }_{-} 5,0$ \\
7 & $5,0{ }_{-} 5,5$ \\
8 & $5,5{ }_{-} 6,0$ \\
\hline
\end{tabular}

$\mathrm{p}<0,05)$ e outubro $\left(x^{2}=4,76, \mathrm{p}<0,05\right)$ (Figura 1). Quanto ao tamanho, o comprimento total das fêmeas variou de 2,8 a $5 \mathrm{~cm}$ enquanto machos variaram de 2,8 a $5,9 \mathrm{~cm}$. Houve predomínio significativo de fêmeas na classe de comprimento 1 e de machos nas classes de comprimento 6,7 e 8 (Figura 2). $\mathrm{OL}_{50}$ de machos e fềmeas foi estimado dentro da classe de comprimento $3(3 \vdash 3,5 \mathrm{~cm})$ e o $\mathrm{L}_{100}$ de machos e fêmeas foi estabelecido dentro da classe de comprimento $6(4,5 \vdash 5 \mathrm{~cm})$ (Figuras $3 \mathrm{e} 4)$.
As maiores freqüências de fêmeas reprodutivas foram encontradas nos meses de setembro e dezembro e as maiores freqüências de machos reprodutivos foram encontradas em dezembro e janeiro (Figuras 5 e 6). Os maiores valores de médias mensais da relação gonadossomática (RGS) para fêmeas foi encontrado em janeiro (RGS $=6,67)$ e em outubro para os machos (RGS=2,56) (Figura 7). 


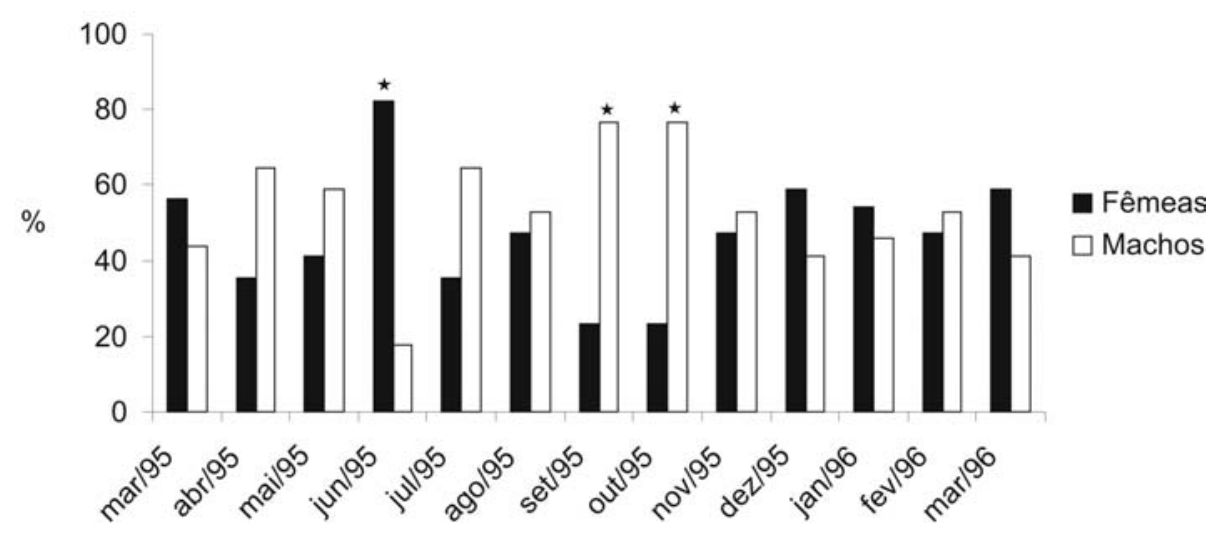

FIGURA 1 - Variação mensal da proporção sexual de Mimagoniates microlepis no rio Colônia Pereira $*=x$ significativo $(p<0,05)$

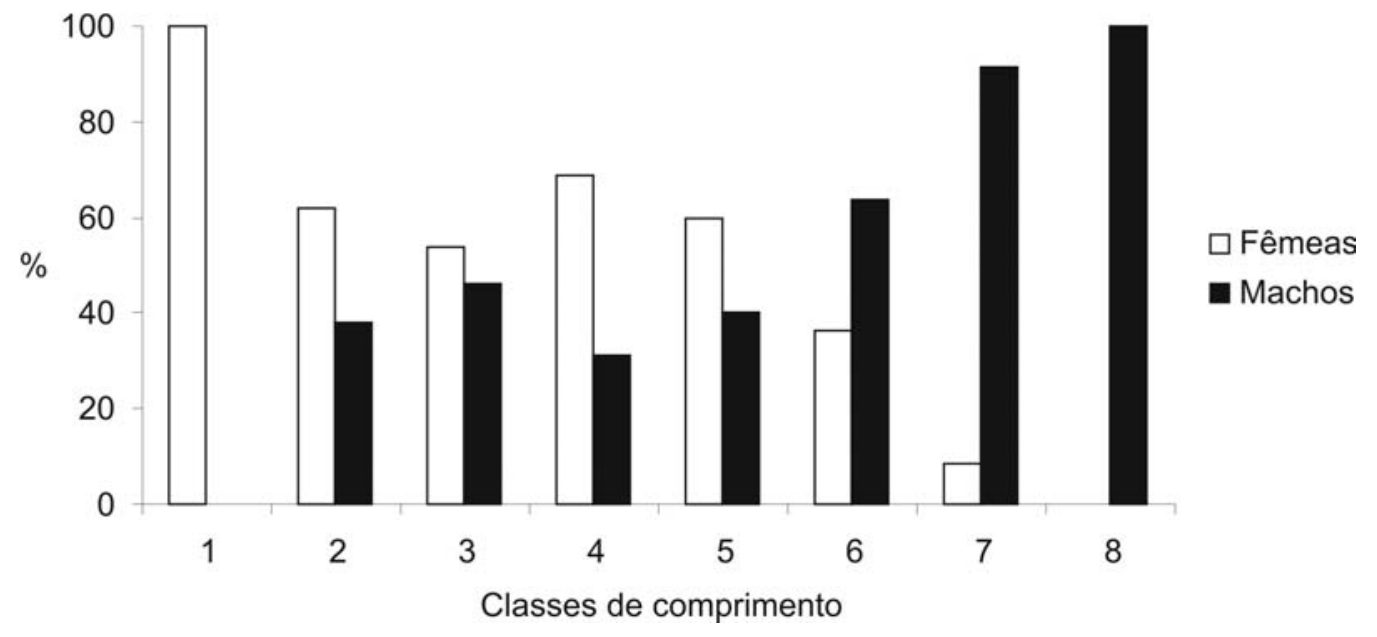

FIGURA 2 - Variação da proporção sexual por classes de tamanho de Mimagoniates microlepis no rio Colônia Pereira

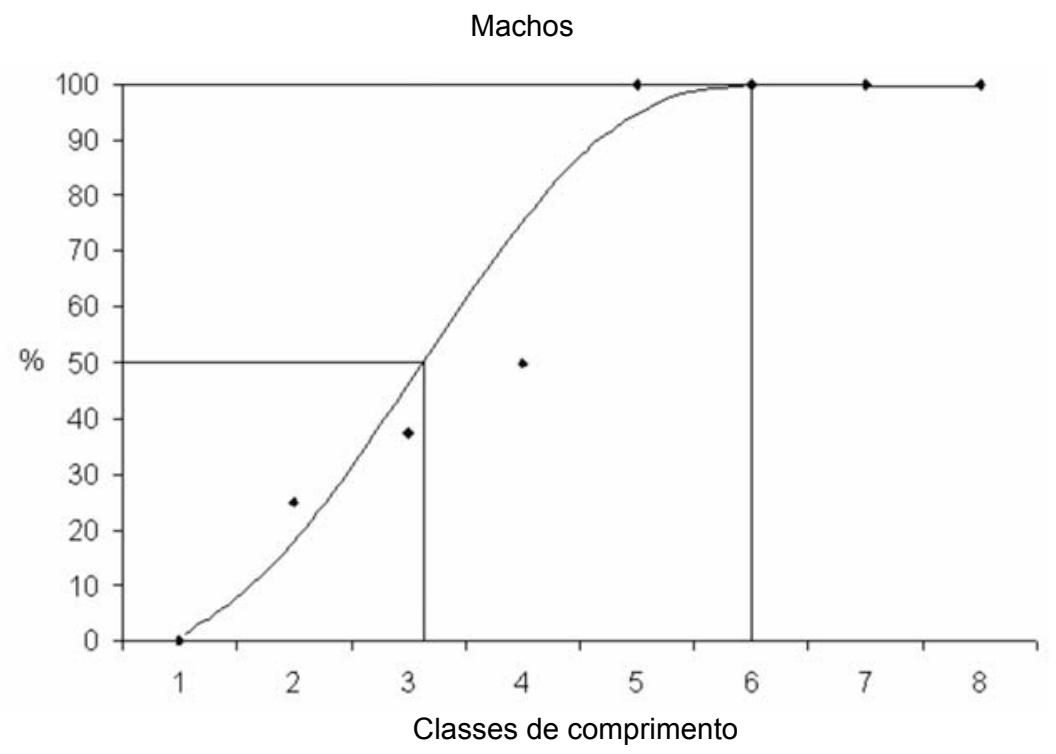

FIGURA 3 - L50 e L100 de machos de Mimagoniates microlepis no rio Colônia Pereira 
Fêmeas

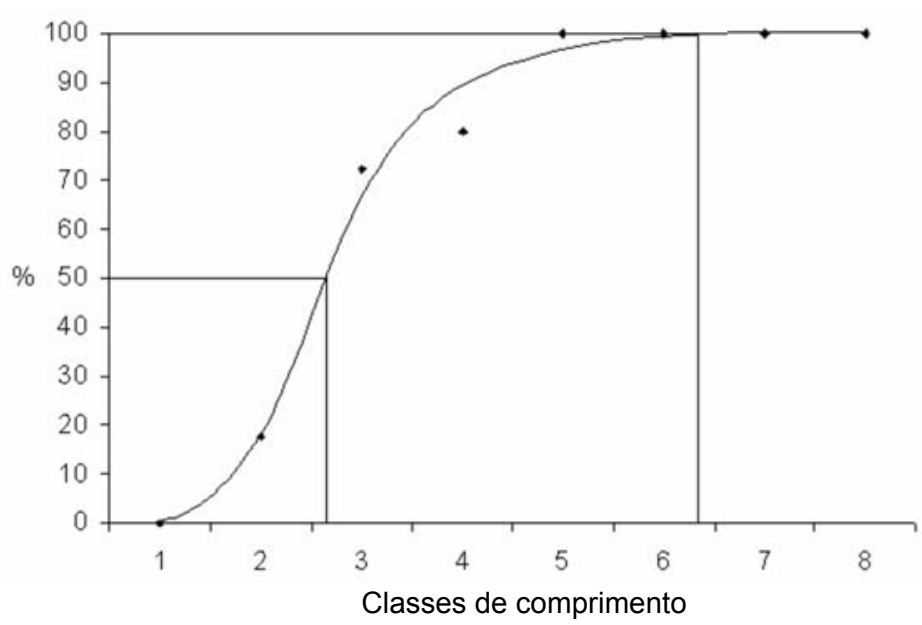

FIGURA 4 - L50 e L100 de fềmeas de Mimagoniates microlepis no rio Colônia Pereira

Discussão

Amaior parte das populações possui número de machos e fêmeas aproximadamente iguais quando se observa a população como um todo, no entanto quando são realizadas análises mais detalhadas, é possível que sejam observadas diferenças na proporção sexual de uma determinada espécie (11). Fatores como Fêmeas

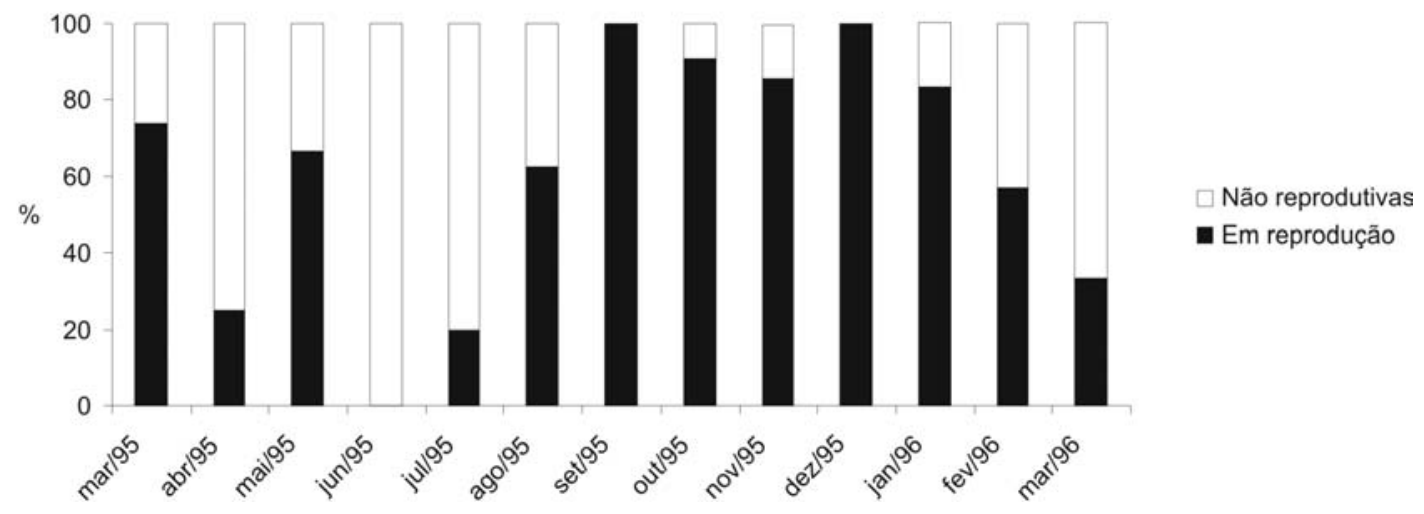

FIGURA 5 - Freqüência de fềmeas de Mimagoniates microlepis em atividade reprodutiva no rio Colônia Pereira Machos

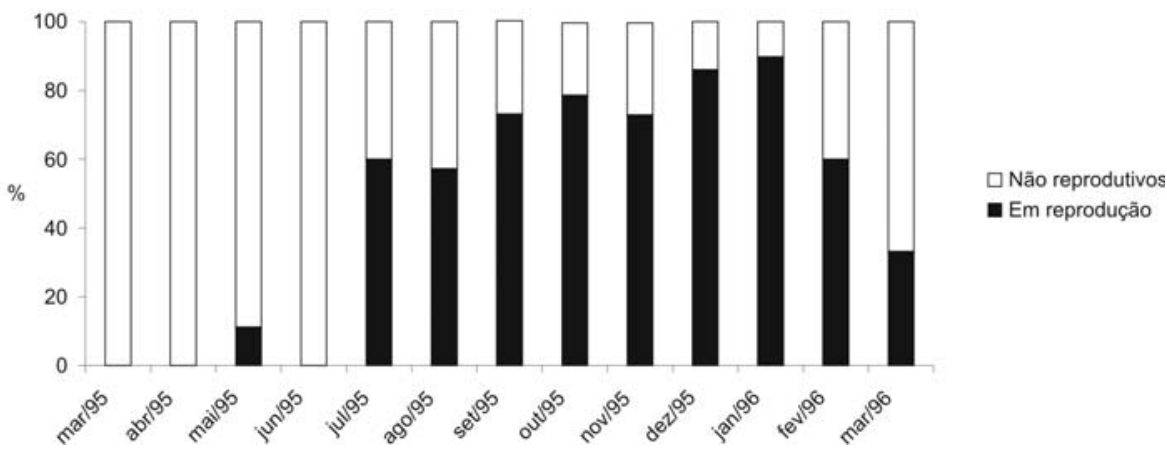

FIGURA 6 - Freqüência de machos de Mimagoniates microlepis em atividade reprodutiva no rio Colônia Pereira 


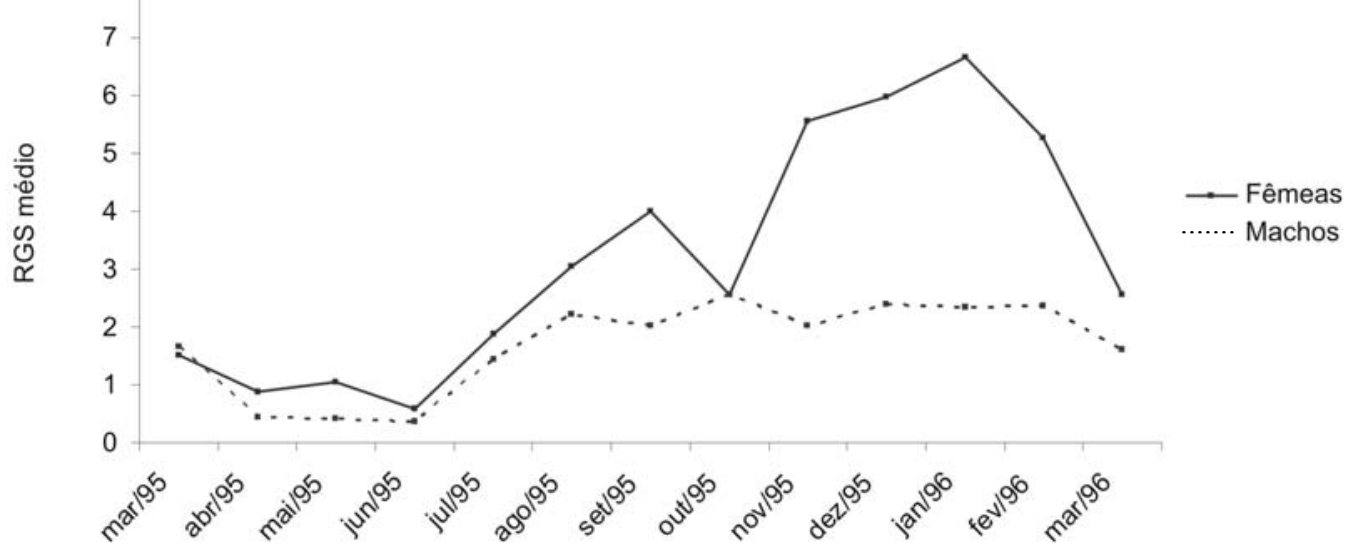

\section{FIGURA 7 - Variação mensal de RGS para machos e fềmeas de Mimagoniates microlepis no rio Colônia Pereira}

mortalidade e taxa de crescimento podem atuar de maneira diferenciada sobre machos e fêmeas, provocando diferenças em suas proporções e é possível que tais fatores tenham importância variada ao longo do desenvolvimento ontogenético (1). Aspectos comportamentais também podem ter influência sobre a proporção sexual observada, por exemplo, fêmeas de Pimelodella pappenheimi em busca de locais adequados para desova tornam-se mais difíceis de capturar, provocando a queda de sua proporção durante o período reprodutivo (12).

Como esperado, a proporção sexual de $M$. microlepis para o período como um todo foi de 1:1, porém houve predomínio de machos em dois meses que correspondem ao início da época reprodutiva. $M$. microlepis, entre outros, Glandulocaudinaes apresenta comportamento agonístico e de coorte elaborados. As atividades agressivas incluem mordidas, exibições laterais, batidas de cauda e perseguições (13). É provável que a competição entre machos pelo acesso as fêmeas durante a época reprodutiva torne-os mais conspícuos e suscetíveis à captura, alterando a proporção sexual em seu favor. Também foi constatada maior proporção de fêmeas em junho, mês onde são encontradas as maiores freqüências de fêmeas não reprodutivas e os menores valores de RGS, caracterizando o período como o de menor atividade reprodutiva durante o estudo. Durante o ciclo de vida, a energia obtida por meio da alimentação é alocada de forma diferenciada para o desenvolvimento somático, armazenamento de reservas e para o desenvolvimento de estruturas reprodutivas (1). O tempo e a energia despendidos pelas fêmeas durante a coorte e desenvolvimento embrionário podem causar queda de reservas energéticas e déficit no desenvolvimento somático. É provável que o período após a reprodução seja caracterizado por intenso esforço das fêmeas para obtenção de alimento e recuperação de energia, o que pode refletir em maior capturabilidade e conseqüentemente maior proporção em relação aos machos.

A análise da proporção sexual por classes de tamanho evidencia um claro dimorfismo sexual de tamanho, sendo que os machos atingem tamanhos maiores que as fêmeas. Estudos de peixes apontam como vantagens seletivas para machos de maior tamanho a capacidade de vencer confrontos, maior acesso às fêmeas e ocupação de melhores territórios, $\mathrm{e}$ possivelmente o dimorfismo sexual de tamanho de $M$. microlepis esteja associado a um ou mais destes fatores $(14,15,16)$.

O comprimento de primeira maturação é uma tática reprodutiva que está intimamente relacionada ao crescimento (1). De fato, podemos entender o momento da primeira maturação em termos dos custos e benefícios de se reproduzir em uma determinada idade e comprimento (11). Quando a primeira maturação é atingida em uma idade precoce, aumenta-se a representatividade genética na geração seguinte, porém, isso representa um custo adicional, devido à fecundidade ser menor em indivíduos menores e, provavelmente, existirá uma exposição a uma maior gama de predadores (1). Por outro lado, em ambientes favoráveis, o adiamento da maturação pode aumentar a fecundidade e diminuir a mortalidade dos jovens. Outro aspecto importante é o de que várias espécies de peixes são muito plásticas em seu ambiente e 
podem mudar a alocação de recursos para crescer ou para se reproduzir de acordo com as condições ambientais e sociais (17). De acordo com Stearns e Crandall (18), a maturação ocorre ao longo de uma trajetória de idade e tamanho que depende das condições demográficas e é determinada tanto pelos genes como pelo ambiente. O comprimento de primeira maturação e o $\mathrm{L}_{100}$ de $M$. microlepis ocorreu nas mesmas classes de comprimento para ambos os sexos, $\mathrm{L}_{50}$ entre 3 e $3,5 \mathrm{~cm} \mathrm{e} \mathrm{L}_{100}$ entre 4,5 e $5 \mathrm{~cm}$. Portanto apesar dos machos atingirem tamanhos maiores, o início da maturação ocorre em comprimento semelhante ao das fêmeas. A escassez de estudos semelhantes com a espécie em outras áreas dificulta comparações, porém a ampla distribuição de $M$. microlepis sugere que estudos em áreas distintas quanto à temperatura e disponibilidade de alimento devam refletir em diferenças nesta tática.

O período reprodutivo e sua duração são fundamentais para compreensão da história de vida e classicamente são associados à competição intraespecífica por locais de desova, disponibilidade de alimento, história evolutiva e flutuações de fatores abióticos (19). Estudos sobre o comportamento reprodutivo de Characiformes da América do Sul apontam para o nível fluviométrico como sendo o fator preponderante na delimitação do período de reprodução na bacia amazônica, por outro lado, na bacia do rio Paraná, as flutuações de temperatura em conjunto com os níveis fluviométricos parecem ser fatores determinantes sobre ciclos reprodutivos (20). Em outras bacias, as informações são escassas, no entanto, em rios litorâneos, a importância do período de chuvas foi reconhecida em estudos reprodutivos de alguns Siluriformes $(12,21)$.

O período reprodutivo de $M$. microlepis ocorreu durante a primavera e o verão. A primavera caracteriza-se pelo aumento da temperatura em relação ao inverno e o verão caracteriza-se principalmente pelo aumento da pluviosidade e, portanto, do nível fluviométrico. Períodos reprodutivos semelhantes foram observados em estudos de Characidaes no Rio Grande do Sul. Gonçalves et al. (22) estudaram o período reprodutivo de Aphyocharax anisiti eAzevedo et al. (23) descreveram a biologia reprodutiva do Glandulocaudine Diapoma speculiferum. Em ambos os estudos, houve correlação do período reprodutivo com a variação da temperatura e do fotoperíodo e é provável que tais fatores também sejam importantes na determinação do período reprodutivo de M. microlepis.
A sazonalidade reprodutiva encontrada corrobora com a hipótese de Burns (7) de que uma das principais vantagens evolutivas da inseminação é a capacidade de se separar os eventos de inseminação e desova, possibilitando o aproveitamento de características favoráveis de períodos secos e períodos chuvosos. É provável que a temperatura e o fotoperíodo sejam os principais fatores exógenos preditivos e sinalizem o início do período reprodutivo, já o aumento dos níveis fluviométricos provavelmente é o fator sincronizador, sinalizando condições favoráveis à desova. A inseminação deve ocorrer enquanto os níveis da água ainda são baixos, maximizando a probabilidade de encontros co-específicos e o crescimento dos jovens ocorre quando os níveis da água são mais altos, oferecendo maior disponibilidade de alimento e abrigo contra predadores.

Constatamos, então, que as diferenças na proporção sexual devem ter ocorrido principalmente em decorrência de aspectos comportamentais ligados à sazonalidade reprodutiva e que $M$. microlepis apresenta um período reprodutivo com aproximadamente seis meses, sincronizado direta ou indiretamente ao regime das chuvas. A capacidade de inseminação e retenção de espermatozóides para posterior desova é provavelmente uma das principais adaptações reprodutivas da espécie e exemplifica a plasticidade e capacidade de adaptação a variáveis ambientais em função de reproduzir-se e manter populações viáveis.

\section{Referências}

1. Vazzoler, AEA. Biologia da reprodução de peixes Teleósteos: teoria e prática. Maringá, PR. EDUEM; 1996.

2. Nakatani K, Agostinho AA, Baumgartner G, Bialetzki A, Sanches PV, Makrakis MC, et al. Ovos e larvas de peixes de água doce. Maringá, PR, EDUEM; 2001.

3. Myers N, Mittermeier RA, Mittermeier CG, Fonseca GA, Kent J. Biodiversity hotspots for conservation priorities. Nature. 2000; 403:853-858.

4. Weitzman SH, Menezes NA, Weitzman MJ. Phylogenetic biogeography of the Glandulocaudini (Teleostei, Characiformes, Characidae) with coments on the distribution of freshwater fishes in Eastern and Southeastern Brazil. In: Workshop on neotropical distribution patterns. Rio de Janeiro: Acad. Brasileira de Ciências; 1988. p. 379-427. 
5. Sant'Anna JFM, Almeida MC, Vicari MR, Shibatta OA, Artoni RF. Levantamento rápido de peixes em uma lagoa marginal do rio Imbituva na bacia do alto rio Tibagi, Paraná, Brasil. Ci. Biol. Saúde. 2006; 12(1):39-46.

6. Menezes NA. Estudo de caso: subfamília Glandulocaudine (Teleostei: Characiformes, Characidae). In: Situação atual e perspectivas da ictiologia no Brasil. Documento do $6^{\circ}$ Encontro Brasileiro de Ictiologia. 1992; Maringá: UEM NUPELIA; 1992. p. 39-41.

7. Burns JR, Weitzman SH, Malabarba LR. Insemination in eight species of Cheirodontine fishes (Teleostei: Characidae: Cheirodontinae). Copeia. 1997; (2):433-438.

8. Ministério do Meio Ambiente \& Secretaria de Recursos Hídricos. Plano nacional de recursos hídricos: panorama e estado dos recursos hídricos do Brasil: Brasília; 2006. v. 1.

9. Köppen GW. Climatologia. In: IAPAR cartas climáticas básicas do Estado do Paraná. Instituto Agronômico do Paraná. Londrina; 1978.

10. Vieira S. Introdução a bioestatística. Rio de Janeiro: Campus; 1991.

11. Ricklefs RE. A economia da natureza. $3^{\mathrm{a}}$ ed. Rio de Janeiro: Guanabara Koogan; 1996.

12. Amaral MF, Aranha JMR, Menezes MS. Reproduction of the freshwater catfish Pimelodella pappenheimi in southern Brazil. Stud Neotrop Fauna \& Environm. 1998; 33:106-110.

13. Nelson K. Behaviour and morphology in the Glandulocaudinae fishes (Ostariophysi, Characidae). University of California Publications in Zoology. 1964; 75(2):59-102.

14. Chelappa S, Yamamoto ME, Cacho MSRF, Huntingford FA. Prior residence, body size and the dynamic of territorial disputes between male freshwater angelfish. J Fish Biol. 1999; 55:1163-1170.
15. Pyron M. Sexual size dimorphism and phylogeny in North American minnows. J Linn Soc Lond Zool. 1996; 57:327-341.

16. Jaroensutasinee M, Jaroensutasinee K. Sexual size dimorphism and male contest in wild Siamese fighting fish. J Fish Biol. 2001; 59:1614-1621.

17. Lowe-McConnell RH. Estudos ecológicos de comunidades de peixes tropicais. São Paulo: EDUSP; 1999.

18. Stearns SC, Crandall RE. Plasticity for age and size at sexual maturity: a life history response to unavoidable stress. In: Ed Potts, GW and Wootton, RJ. editor. Fish Reproduction: Strategies and Tactics. London: Academic Press; 1984. p. 410.

19. Kramer DL. Reproductive seasonality in the fishes of a tropical stream. Ecology. 1978; 59:976-985.

20. Vazzoler AEAM, Menezes NA. Síntese de conhecimentos sobre o comportamento reprodutivo dos Characiformes da América do Sul (Teleostei, Ostariophysi). Rev Brasil Biol. 1992; 52(4):627-640.

21. Menezes MS, Caramaschi EP. Características reprodutivas de Hypostomus Grupo H. punctatus no rio Ubatiba, Maricá, RJ (Osteichthyes, Siluriformes). Rev Brasil Biol. 1994. 54:503-513.

22. Gonçalves TK, Azevedo MA, Malabarba LR, Fialho CB. Reproductive biology and development of sexually dimorphic structures in Aphyocharax anisitsi (Ostariophysi: Characidae). Neotropical Ichthyology. 2005; 3(3):433-438.

23. Azevedo MA, Malabarba LR, Fialho CB. Reproductive biology of the inseminating Glandulocaudine Diapoma speculiferum Cope (Teleostei: Characidae). Copeia 2000; (4):983-989.

Recebido em/Received in: July 19, 2006 Aceito em/Accepted in: September 5, 2006 